\title{
KINEMATICS OF THE MILKY WAY FROM VELOCITIES OF YOUNG RED CLUMP GIANTS USING THE PMA AND GAIA DR2 DATA
}

\author{
A. B. Velichko, P. N. Fedorov \\ Institute of astronomy of V.N. Karazin Kharkiv national university, \\ Kharkiv, Ukraine, velichko.anna.b@gmail.com
}

\begin{abstract}
Subsample of 19,600 young red clump giants with distances up to $1200 \mathrm{pc}$ was selected from $7.2 \mathrm{mln}$ Gaia DR2 data with radial velocities using the $\mathrm{M}_{\mathrm{G}}$ vs. $\mathrm{G}-\mathrm{K}_{\mathrm{S}}$ diagram. Ages of these stars do not exceed 2 bln years. For this stellar subsample kinematic parameters of the Ogorodnikov-Milne model as well as the $K_{x y}$-term, Solar apex coordinates $\mathrm{L}_{\odot}, \mathrm{B}_{\odot}$ were derived from the $3 \mathrm{D}$ and $2 \mathrm{D}$ Gaia DR2 data as well as from the PMA proper motions. It was found that values of the OMM parameters derived from the 3D and 2D Gaia DR2 data are different. Removing stars with heliocentric distances 0-500 pc make the results consistent. For the 500-1200 pc stellar subsample value of the rotation velocity of the Galaxy at the Solar distance $\mathrm{V}_{\text {rot }}$ derived from the PMA proper motions is $205.2 \pm$ $0.5 \mathrm{~km} \mathrm{~s}^{-1}$ while the values derived from the Gaia DR2 data are noticeably higher: $\mathrm{V}_{\text {rot }}(2 \mathrm{D}$ Gaia DR2) $=$ $217.8 \pm 0.3 \mathrm{~km} \mathrm{~s}^{-1}$ and $\mathrm{V}_{\text {rot }}(2 \mathrm{D}$ Gaia DR2 $)=218.6 \pm$ $0.3 \mathrm{~km} \mathrm{~s}^{-1}$. The $K_{x y}$-term is negative and equal

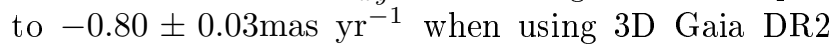
data while it diminishes significantly in case of usage of Gaia DR2 and PMA proper motions.
\end{abstract}

Keywords: Astrometric catalogues, Galactic kinematics, stellar proper motions, stellar radial velocities, Hertzsprung-Russel diagram.

АБСТРАКТ. Використовуючи діаграму $\mathrm{M}_{\mathrm{G}}$ $\left(\mathrm{G}-\mathrm{K}_{\mathrm{S}}\right)$ з 7.2 мільйонів об'єктів Gaia DR2 з відомими променевими швидкостями була виділена підвибірка 19,600 молодих гігантів червоного згущення з відстанями до 1200 пк. Для того, щоб виправити дані за почервоніння і поглинання, використовувалася тривимірна карта поглинань Гончарова. Згідно з теоретичними розрахунками Жірарді, ці зірки мають маси не менше $2-2.5 M_{\odot}$, а значить їх віки не перевищують 2 мільярдів років. Для цієї підвибірки зірок за 2D (з використанням тільки власних рухів) i 3D (власні рухи плюс променеві швидкості) даними Gaia DR2, а також за власними рухам каталогу РМА були отримані кінематичні параметри моделі ОгородніковаМілна, а також параметр розширення-стиснення в галактичної площини $(x, y)-K_{x y}$, і координати апекса Сонця $\mathrm{L}_{\odot}, \mathrm{B}_{\odot}$. Було виявлено, що значення деяких параметрів моделі, отриманих за 2D i 3D даними Gaia DR2, помітно різрізняються між собою. Так, наприклад, значення параметра $M_{12}^{+}$, отриманого шляхом спільного рішення трьох рівнянь моделі Огороднікова-Мілна методом найменших квадратів, на 0.2 мсд $\Gamma^{-1}$ менше, ніж значення, яке було отримане за допомогою спільного рішення рівнянь тільки для власних рухів Gaia DR2. Видалення з вибірки зірок з відстанями 0-500 пк робить результати більш узгодженими. Для підвибірки 500-1200 пк параметри $\omega_{3}$ i $M_{12}^{+}$, отримані за даними Gaia DR2, відповідно рівні

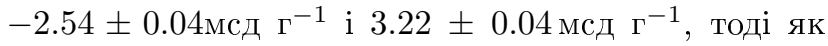
за даними каталогу РМА їх значення становлять $-2.59 \pm 0.06$ мсд $\Gamma^{-1}$ і $2.83 \pm 0.08$ мсд $\Gamma^{-1}$. В результаті значення лінійної швидкості обертання Галактики на відстані Сонця $\mathrm{V}_{\text {rot }}$, яке було отримано за власними рухами РМА, становить $205.2 \pm 0.5 \mathrm{kм}^{-1}$, тоді як значення, отримане за даними Gaia DR2, на 13 км с ${ }^{-1}$ вище: $V_{\text {rot }}$ $($ Gaia DR2 $)=218.2 \pm 0.3 \quad$ км c $c^{-1}$. За даними 3D Gaia DR2 параметр $K_{x y} \in$ негативним і рівним $-0.80 \pm 0.03$ мсд $\Gamma^{-1}$. Його величина по модулю значно зменшується в разі використання власних pyxiв Gaia DR2 i PMA, і в межах $3 \sigma \in$ незначущою. Значення компоненти швидкості Сонця уздовж галактичної осі $y, V_{\odot}$, відносно центроїда зірок має значення $11.59 \pm 0.30 \mathrm{KM} \mathrm{c}^{-1}$ за даними PMA i $13.0 \pm 0.20$ км c$^{-1}$ за даними Gaia DR2. Цей факт $\epsilon$ непрямим свідченням того, що зірки з нашої вибірки дійсно мають віки не більше 2 мільярдів років (Gontcharov, 2012b).

Ключові слова: Астрометричні каталоги, кінематика Галактики, власні рухи зірок, променеві швидкості зірок, діаграма Герцшпрунга-Рассела. 


\section{Introduction}

On April 25, 2018 the second release of the Gaia mission (Gaia DR2) has came out (Gaia collaboration et al., 2016; Gaia collaboration et al., 2018b). Based on 22 month observational time baseline, it provides coordinates, proper motions and parallaxes for more than 1.3 bln stars distributed uniformly through the celestial sphere. Among them, there is a $\sim 7.2 \mathrm{mln}$ stellar subsample with magnitudes $\mathrm{G}<15$ for which median radial velocities (RV) were provided as well. This subsample includes stars that have effective temperatures $\mathrm{T}_{\text {eff }}$ within the range $3550-6900 \mathrm{~K}$ corresponding to FGK spectral types. These data give us a full information about how do stars move in the space.

It is well known that the Galaxy has a complex structure: there are at least four components such as thin, thick disks, halo and buldge. They differ from each other by kinematics, ages, metallicity, $\alpha$-element abundances, and maybe some others. In this study we select stars with ages do not exceeding 2 bln years and therefore belonging to the Galactic thin disk. Stellar ages of the Gaia DR2 RV subsample used are not known but we have took advantage of the known property of the secondary clump of red giants in the colourmagnitude diagram (CMD). Since the works by Girardi et al.(1998) and Girardi (1999), the clump of stars located in the slightly bluer and fainter part of the CMD than the ordinary (main) clump of red giants is recognized as being formed by stars with initial masses $M \geq M_{\text {Hef }} \sim 2-2.5 M_{\odot}$ in the stage of central helium burning ( $\mathrm{CHeB})$. The main difference between giants belonging to the main and secondary clumps is that in the latter case stars reach the $\mathrm{CHeB}$ stage skipping the electron-degenerate core phase after the central hydrogen exhaustion, i.e. helium ignition begins under non-degenerate conditions (Girardi, 1999). Lifetimes of stars with masses $M>2-2.5 M_{\odot}$ do not exceed 2 Gyr. Therefore, following Gontcharov (2012) we refer red giants belonging to the secondary clump to as young red clump giants (YRCG).

The paper is organized as follows. Section 2 presents description of some properties of input data used for analysis of the stellar velocity field. In section 3 the procedure of selection of the young red clump giants is given. Details of usage of the Ogorodnikov-Milne model are presented in section 4 . Kinematic analysis and conclusions are given in sections 5 and 6 respectively.

\section{Input data}

For kinematic analysis the Gaia DR2 RV and PMA catalogues data were used. As was noticed in Introduction, the Gaia DR2 RV subsample contains only FGK-type stars. Positions and parallaxes of these stars were derived with typical uncertainty 0.02 0.04 mas. Their proper motions are evaluated to be better than 0.07 mas $\mathrm{yr}^{-1}$ while the RV precision varies from $0.3 \mathrm{~km} \mathrm{~s}^{-1}$ at $\mathrm{G}_{\mathrm{RVS}}<8$ and $1.8 \mathrm{~km} \mathrm{~s}^{-1}$ at $\mathrm{G}_{\mathrm{RVS}}=11.75$. Systematic RV errors are expected to be from less than $0.1 \mathrm{~km} \mathrm{~s}^{-1}$ at $\mathrm{G}_{\mathrm{RVS}}<9$ to $0.5 \mathrm{~km} \mathrm{~s}^{-1}$ at $\mathrm{G}_{\mathrm{RVS}}=11.75$. According to Gaia collaboration et al. (2018b), the second realisation of the Gaia celestial reference frame (Gaia-CRF2) at the faint end $(G \sim 19)$ is aligned with the ICRF to about 0.02 mas at epoch J2015.5 and non-rotating with respect to the ICRF to within 0.02 mas $\mathrm{yr}^{-1}$.

The PMA (Proper Motion Absolute) catalogue was derived in the laboratory of astrometry of Institute of astronomy of V.N. Karazin Kharkiv national university (Akhmetov et al., 2017) from combination of Gaia DR1 and 2MASS catalogues. It contains positions, proper motions, and $\mathrm{G}, \mathrm{J}, \mathrm{H}, \mathrm{K}_{\mathrm{S}}$ photometry for more than $420 \mathrm{mln}$ objects covered the whole celestial sphere including the Galactic plane. From this stellar sample $\sim 6.9 \mathrm{mln}$ stars that are common with the Gaia DR2 RV subsample were selected. Typical uncertainty of stellar positions is 10 mas. Proper motions are estimated to have errors of the

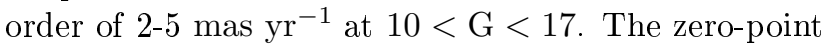
of the proper motions was established using $1.6 \mathrm{mln}$ extragalactic sources. It has been shown (Akhmetov et al., 2017) that the PMA coordinate axes are non-rotating with respect to extragalactic sources from the LQAC3 and ICRF catalogues.

\section{Selection of young red clump giants}

All YRCG are in the Galactic plane. Therefore it is necessary to take into account interstellar extinction. To do this, the Gontcharov's 3D extinction map (Gontcharov, 2017) was used. This map is limited by distance to $1200 \mathrm{pc}$ and by Galactic coordinate $\mathrm{Z} \pm 600 \mathrm{pc}$. It is organized as follows. At every point of space with galactic coordinates $x, y, z$ (or $l, b, r)$ values of $\mathrm{E}\left(\mathrm{J}-\mathrm{K}_{\mathrm{S}}\right), \mathrm{E}(\mathrm{B}-\mathrm{V}), \mathrm{R}_{\mathrm{V}}$ and $\mathrm{A}_{\mathrm{V}}$ are provided. The resolution of the map is $50 \times 50 \times 50 \mathrm{pc}$. To compute extinction and reddening at a given point $\left(x^{*}, y^{*}, z^{*}\right)$ the trilinear interpolation formula 1 was used.

$$
\begin{aligned}
& \quad f\left(x^{*}, y^{*}, z^{*}\right) \simeq \\
& a \quad\left[\quad f\left(x_{1}, y_{1}, z_{1}\right)\left(x_{2}-x^{*}\right)\left(y_{2}-y^{*}\right)\left(z_{2}-z^{*}\right)+\right. \\
& +f\left(x_{1}, y_{1}, z_{2}\right)\left(x_{2}-x^{*}\right)\left(y_{2}-y^{*}\right)\left(z^{*}-z_{1}\right)+ \\
& +f\left(x_{1}, y_{2}, z_{1}\right)\left(x_{2}-x^{*}\right)\left(y^{*}-y_{1}\right)\left(z_{2}-z^{*}\right)+ \\
& \quad+f\left(x_{1}, y_{2}, z_{2}\right)\left(x_{2}-x^{*}\right)\left(y^{*}-y_{1}\right)\left(z^{*}-z_{1}\right)+ \\
& \quad+f\left(x_{2}, y_{1}, z_{1}\right)\left(x^{*}-x_{1}\right)\left(y_{2}-y^{*}\right)\left(z_{2}-z^{*}\right)+ \\
& +f\left(x_{2}, y_{1}, z_{2}\right)\left(x^{*}-x_{1}\right)\left(y_{2}-y^{*}\right)\left(z^{*}-z_{1}\right)+ \\
& +f\left(x_{2}, y_{2}, z_{1}\right)\left(x^{*}-x_{1}\right)\left(y^{*}-y_{1}\right)\left(z_{2}-z^{*}\right)+ \\
& \left.\quad+f\left(x_{2}, y_{2}, z_{2}\right)\left(x^{*}-x_{1}\right)\left(y^{*}-y_{1}\right)\left(z^{*}-z_{1}\right)\right](1)
\end{aligned}
$$


where

$$
a=\frac{1}{\left(x_{2}-x_{1}\right)\left(y_{2}-y_{1}\right)\left(z_{2}-z_{1}\right)}
$$

YRCG can be identified using the colour-magnitude diagram in the $\mathrm{M}_{\mathrm{G}}-\left(\mathrm{G}-\mathrm{K}_{\mathrm{S}}\right)$ coordinates. The red clump region in the CMD for stars with low extinction $\mathrm{E}\left(\mathrm{J}-\mathrm{K}_{\mathrm{S}}\right)<0.05$ is shown in Fig. 1. It can be seen that there is a weak concentration of stars inside the ellipse shown by black solid line. These are the YRCG. We suggested that a star belongs to the secondary clump if it falls inside the ellipse centered at $\left(\mathrm{M}_{\mathrm{G}}, \mathrm{G}-\mathrm{K}_{\mathrm{S}}\right)=(0.6,1.9)$ with semiaxes $\left(\Delta \mathrm{M}_{\mathrm{G}}, \Delta\left(\mathrm{G}-\mathrm{K}_{\mathrm{S}}\right)\right)=(0.5,0.13)$. All bed quality objects with $\sigma_{\varpi} / \varpi>0.2$ were removed from the sample. As a result 19,600 YRCG with distances up to 1200 pc and $\mathrm{Z} \pm 600 \mathrm{pc}$ were selected.

The Gontcharov's map does not provide reddening for colour $G-K_{S}$, so we have found empirical relation between $\mathrm{E}\left(\mathrm{J}-\mathrm{K}_{\mathrm{S}}\right)$ and $\mathrm{E}\left(\mathrm{G}-\mathrm{K}_{\mathrm{S}}\right)$ :

$$
\begin{aligned}
& \mathrm{E}\left(\mathrm{G}-\mathrm{K}_{\mathrm{S}}\right)=-904.2 \mathrm{E}\left(\mathrm{J}-\mathrm{K}_{\mathrm{S}}\right)^{4}+271.5 \mathrm{E}\left(\mathrm{J}-\mathrm{K}_{\mathrm{S}}\right)^{3} \\
& -12.1 \mathrm{E}\left(\mathrm{J}-\mathrm{K}_{\mathrm{S}}\right)^{2}+1.1 \mathrm{E}\left(\mathrm{J}-\mathrm{K}_{\mathrm{S}}\right)
\end{aligned}
$$

\section{Usage of the Ogorodnikov-Milne model}

All calculations were made in the rectangular heliocentric Galactic coordinate system the main plane of which coincides with the Galactic plane. The $\mathrm{x}$ axis is directed towards the Galactic centre $\left(l=0^{\circ}, b=0^{\circ}\right)$, hereafter it will be referred to as the $\mathrm{x}$ or 1 axis. The $\mathrm{y}$ or 2 axis is directed towards direction of Galactic rotation $\left(l=90^{\circ}, b=0^{\circ}\right)$ while $\mathrm{z}$ axis towards the direction parallel to one from centre of the Galaxy to its North pole $\left(b=0^{\circ}\right)$.

To analyse the stellar velocity field the OgorodnikovMilne model (OMM) was used (Ogorodnikov, 1965).

$$
\mathbf{V}=\mathbf{V}_{0}+\mathbf{\Omega} \times \mathbf{r}+\mathbf{M}^{+} \times \mathbf{r}
$$

The OMM model contains 12 kinematic parameters:

$X_{\odot}, Y_{\odot}, Z_{\odot}$ are the Solar motion components relative to the centroid; $\omega_{1}, \omega_{2}, \omega_{3}$, are components of the rigid-body rotation vector $\Omega ; M_{12}^{+}, M_{13}^{+}, M_{23}^{+}$are components of the tensor $\mathbf{M}^{+}$characterizing velocities of deformations in the $(\mathrm{x}, \mathrm{y}),(\mathrm{x}, \mathrm{z})$ and $(\mathrm{y}, \mathrm{z})$ Galactic planes; $M_{11}^{+}, M_{22}^{+}, M_{33}^{+}$are components of the tensor $\mathbf{M}^{+}$responsible for velocities of contraction-expansion of the stellar sample used.

Projecting the equation 3 onto the unit vectors of the Galactic coordinate system yields the following system of equations

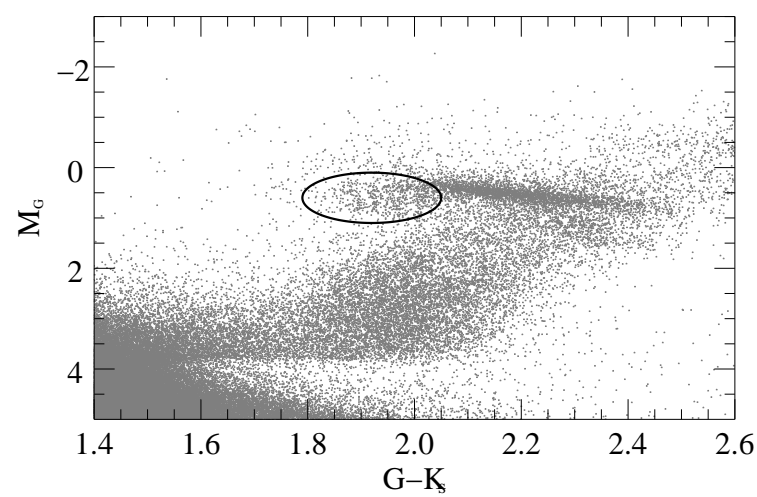

Figure 1: Zoom of the CMD $\mathrm{M}_{\mathrm{G}}-\left(\mathrm{G}-\mathrm{K}_{\mathrm{S}}\right)$. YRCG are inside the ellipse.

$$
\begin{aligned}
\eta \mu_{l} \cos b & =X_{\odot} / r \sin l-Y_{\odot} / r \cos l-\omega_{1} \sin b \cos l- \\
& -\omega_{2} \sin b \sin l+\omega_{3} \cos b+M_{12}^{+} \cos b \cos 2 l- \\
& -M_{13}^{+} \sin b \sin l+M_{23}^{+} \sin b \cos l- \\
& -0.5 M_{11}^{+} \cos b \sin 2 l+0.5 M_{22}^{+} \cos b \sin 2 l \\
\eta \mu_{b}= & X_{\odot} / r \cos l \sin b+Y_{\odot} / r \sin l \sin b-Z_{\odot} / r \cos b+ \\
& +\omega_{1} \sin l-\omega_{2} \cos l-0.5 M_{12}^{+} \sin 2 b \sin 2 l- \\
& -M_{13}^{+} \cos 2 b \cos l+M_{23}^{+} \cos 2 b \sin l- \\
& -0.5 M_{11}^{+} \sin 2 b \cos ^{2} l-0.5 M_{22}^{+} \sin 2 b \sin ^{2} l+ \\
& +0.5 M_{33}^{+} \sin 2 b \\
V_{r} / r= & -X_{\odot} / r \cos l \cos b-Y_{\odot} / r \sin l \cos b- \\
& -Z_{\odot} / r \sin ^{2} b+M_{13}^{+} \sin _{2 b} \cos l+M_{23}^{+} \sin _{2} b \sin l+ \\
& +M_{12}^{+} \cos ^{2} b \sin 2 l+M_{11}^{+} \cos ^{2} b \cos ^{2} l+ \\
& +M_{22}^{+} \cos ^{2} b \sin ^{2} l+M_{33}^{+} \sin ^{2} b
\end{aligned}
$$

Where $\eta=4.74$ is the conversion factor from mas $\mathrm{yr}^{-1}$ to $\mathrm{kms}^{-1} \mathrm{kpc}^{-1}, \mu_{l}, \mu_{b}$ are proper motions in mas $\mathrm{yr}^{-1}, V_{r}$ are radial velocities in $\mathrm{km} \mathrm{s}^{-1}$.

When proper motions only are used, one of diagonal elements of the deformation matrix $\mathbf{M}^{+}$remains undetermined. Therefore, only differences $M_{11}^{*}=$ $M_{11}^{+}-M_{22}^{+}$and $M_{33}^{*}=M_{33}^{+}-M_{22}^{+}$can be derived suggesting that $M_{22}^{+}=0$. Values of the $K_{\mathrm{xy}}$-term characterizing contraction-expansion of the stellar sample in the $x, y$ Galactic plane were derived as well: $K=0.5\left(M_{11}^{+}+M_{22}^{+}\right)$. In the case of usage of proper motions only the $K$-term can be evaluated using the following equation: $K=0.5\left(M_{11}^{*}-2 M_{33}^{*}\right)$. The $M_{12}^{+}$ and $\omega_{3}$ parameters are analogues of the Oort constants A and B from the simplified Oort-Lindblad kinematic model. The linear rotation velocity of the Galaxy $\mathrm{V}_{\text {rot }}$ at the Solar distance $\mathrm{R}_{\odot}$ can be derived from combination of these two parameters by the following relation: $\mathrm{V}_{\text {rot }}=\left(M_{12}^{+}-\omega_{3}\right) \eta \mathrm{R}_{\odot}$. The value of $\mathrm{R}_{\odot}$ is assumed to be equal to $8.0 \pm 0.2 \mathrm{kpc}$ (Vallée, 2017).

In addition, the Solar apex coordinates $\mathrm{L}_{\odot}, \mathrm{B}_{\odot}$ were estimated. 
Table 1: The OMM kinematic parameters derived in this work.

\begin{tabular}{|ll|ccc|ccc|}
\hline & & \multicolumn{3}{|c}{$0-1200 \mathrm{pc}$} & \multicolumn{3}{c}{$500-1200 \mathrm{pc}$} \\
Parameter & Unit & Gaia, 3D & Gaia, 2D & PMA, 2D & Gaia, 3D & Gaia, 2D & PMA, 2D \\
\hline $\mathrm{X}_{\odot}$ & $\mathrm{km} \mathrm{s}^{-1}$ & $9.83 \pm 0.13$ & $9.32 \pm 0.17$ & $9.89 \pm 0.19$ & $10.89 \pm 0.15$ & $10.83 \pm 0.19$ & $11.62 \pm 0.26$ \\
$\mathrm{Y}_{\odot}$ & $\mathrm{km} \mathrm{s}^{-1}$ & $11.64 \pm 0.13$ & $11.71 \pm 0.18$ & $10.6 \pm 0.21$ & $12.63 \pm 0.15$ & $13.40 \pm 0.22$ & $11.59 \pm 0.30$ \\
$\mathrm{Z}_{\odot}$ & $\mathrm{km} \mathrm{s}^{-1}$ & $7.80 \pm 0.13$ & $7.72 \pm 0.15$ & $7.66 \pm 0.17$ & $7.29 \pm 0.15$ & $7.26 \pm 0.16$ & $7.46 \pm 0.21$ \\
\hline$\omega_{1}$ & mas yr $^{-1}$ & $0.37 \pm 0.10$ & $0.44 \pm 0.11$ & $0.50 \pm 0.13$ & $0.09 \pm 0.08$ & $0.05 \pm 0.09$ & $0.12 \pm 0.12$ \\
$\omega_{2}$ & mas yr $^{-1}$ & $-0.73 \pm 0.10$ & $-0.72 \pm 0.11$ & $-0.92 \pm 0.13$ & $-0.55 \pm 0.08$ & $-0.45 \pm 0.09$ & $-0.68 \pm 0.12$ \\
$\omega_{3}$ & mas yr $^{-1}$ & $-2.54 \pm 0.10$ & $-2.58 \pm 0.06$ & $-2.62 \pm 0.07$ & $-2.55 \pm 0.04$ & $-2.53 \pm 0.04$ & $-2.59 \pm 0.06$ \\
\hline$M_{23}^{+}$ & mas yr $^{-1}$ & $-0.26 \pm 0.10$ & $-0.35 \pm 0.13$ & $-0.43 \pm 0.15$ & $0.03 \pm 0.08$ & $0.10 \pm 0.10$ & $-0.02 \pm 0.14$ \\
$M_{13}^{+}$ & mas yr $^{-1}$ & $-0.55 \pm 0.10$ & $-0.55 \pm 0.13$ & $-0.95 \pm 0.15$ & $-0.41 \pm 0.08$ & $-0.27 \pm 0.10$ & $-0.67 \pm 0.13$ \\
$M_{12}^{+}$ & mas yr $^{-1}$ & $3.24 \pm 0.06$ & $3.04 \pm 0.09$ & $2.70 \pm 0.10$ & $3.22 \pm 0.04$ & $3.22 \pm 0.06$ & $2.83 \pm 0.08$ \\
$M_{11}^{+}\left(M_{11}^{*}\right)$ & mas yr $^{-1}$ & $-1.86 \pm 0.09$ & $-2.19 \pm 0.24$ & $-2.05 \pm 0.19$ & $-1.76 \pm 0.06$ & $-2.00 \pm 0.11$ & $-2.11 \pm 0.16$ \\
$M_{22}^{+}$ & mas yr $^{-1}$ & $0.19 \pm 0.08$ & - & - & $0.16 \pm 0.16$ & - & - \\
$M_{33}^{+}\left(M_{33}^{*}\right)$ & mas yr $^{-1}$ & $-0.06 \pm 0.08$ & $-0.63 \pm 0.23$ & $-0.82 \pm 0.27$ & $-0.23 \pm 0.14$ & $-0.68 \pm 0.17$ & $-2.11 \pm 0.23$ \\
\hline $\mathrm{V}_{\text {rot }}$ & km s $^{-1}$ & $219.1 \pm 0.4$ & $213.1 \pm 0.5$ & $201.65 \pm 0.6$ & $218.6 \pm 0.3$ & $217.8 \pm 0.3$ & $205.2 \pm 0.5$ \\
$\mathrm{~K}$ & mas yr & $-0.84 \pm 0.05$ & $-0.09 \pm 0.04$ & $-0.02 \pm 0.04$ & $-0.80 \pm 0.03$ & $-0.32 \pm 0.14$ & $-0.14 \pm 0.27$ \\
$\mathrm{~L}_{\odot}$ & degree & $49.8 \pm 3.8$ & $51.5 \pm 0.1$ & $47.0 \pm 0.2$ & $49.3 \pm 4.6$ & $51.0 \pm 0.1$ & $44.9 \pm 0.3$ \\
$\mathrm{~B}_{\odot}$ & degree & $27.1 \pm 1.6$ & $27.3 \pm 0.1$ & $27.1 \pm 0.1$ & $23.6 \pm 1.8$ & $22.9 \pm 0.1$ & $24.5 \pm 0.1$ \\
\hline
\end{tabular}
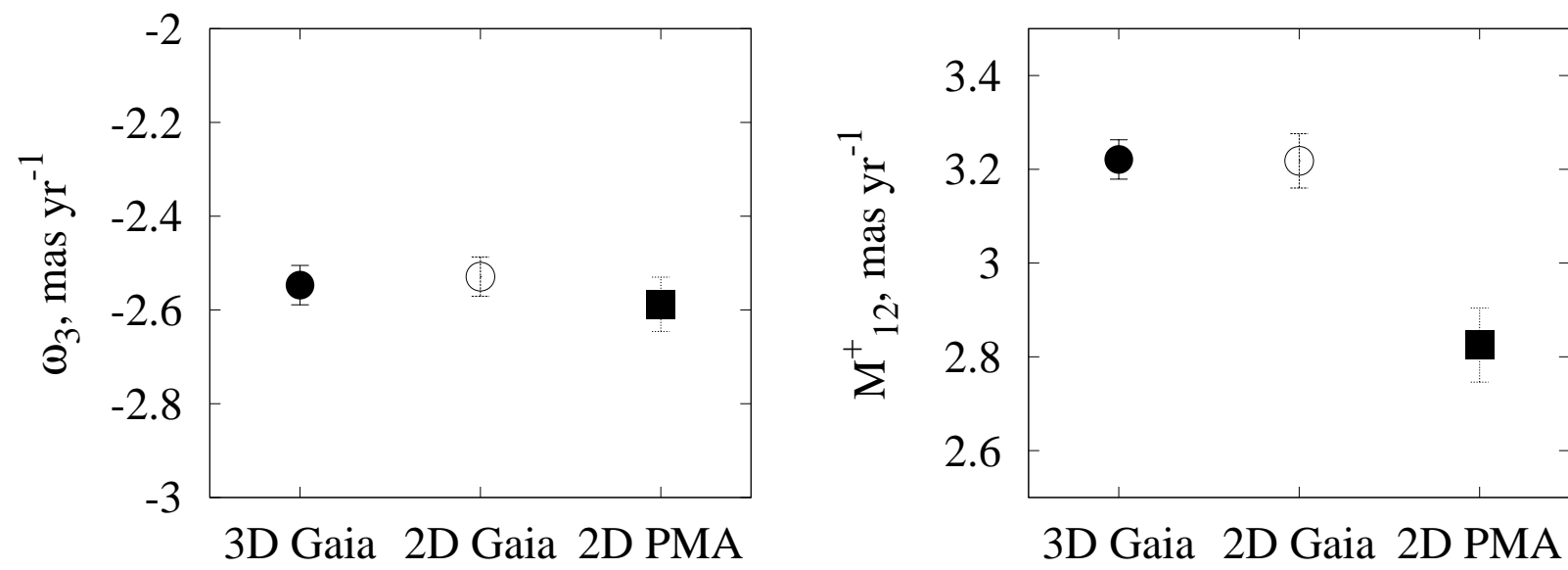

3D Gaia 2D Gaia 2D PMA
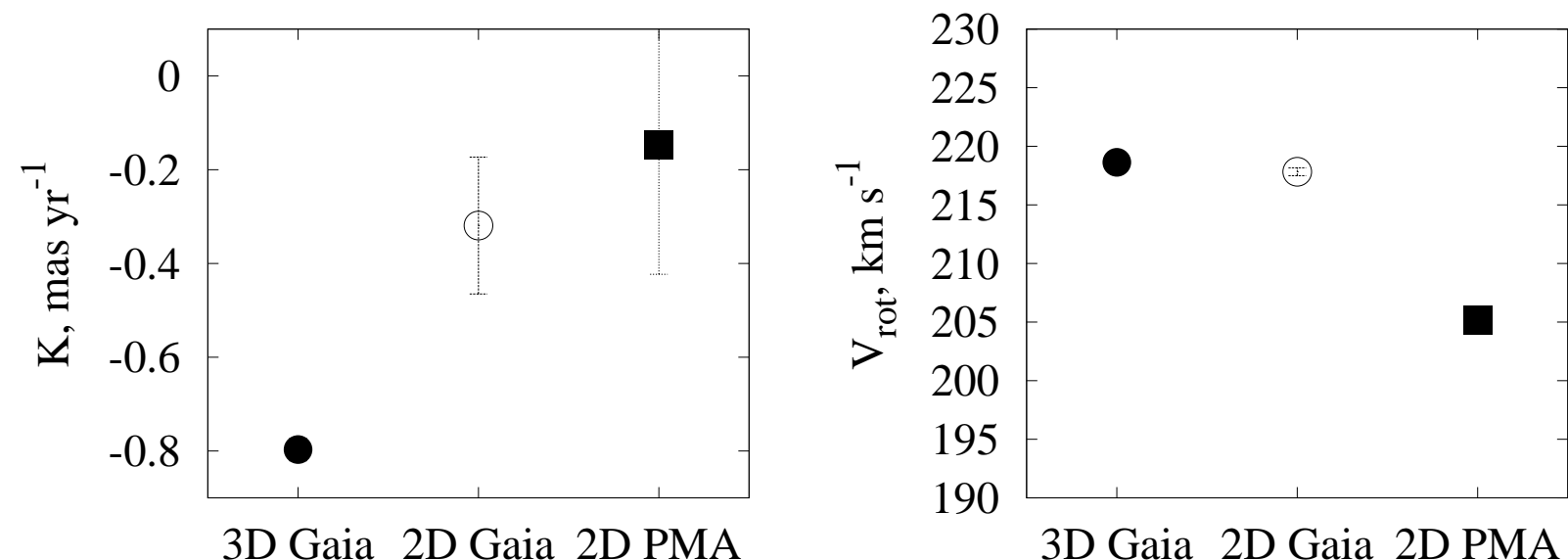

Figure 2: The $\omega_{3}, M_{12}^{+}, \mathrm{V}_{\text {rot }}$ OMM parameters and $K_{x y}$-term derived from the 3D (filled circles), 2D Gaia DR2 (open circles) and PMA (filled squares) data for the 500-1200 pc YRCG subsample. 


\section{Kinematic analysis}

All calculations were performed for the YRCG subsample described in section 3 . The OMM equations 4, 5, 6 were solved by the least square method (LSR) using the Gaia DR2 RV data. This case we refer to as $3 \mathrm{D}$ one, because both proper motions and radial velocities were used. For comparison, the OMM parameters were derived from the Gaia DR2 proper motions only, i.e. by joint solving the equations 4,5 (2D case). The results are given in columns 2, 3 of Table 1 as well as in Fig. 2. It can be seen that values of the $\omega_{3}$ parameter derived from $3 \mathrm{D}$ and $2 \mathrm{D}$ Gaia DR2 data are very close while values of the $M_{12}^{+}$parameter have difference $M_{12}^{+}(3 \mathrm{D})-M_{12}^{+}(2 \mathrm{D})=0.2$ mas $\mathrm{yr}^{-1}$ leading to difference between values of linear Galactic rotation velocity: $\mathrm{V}_{\text {rot }}(3 \mathrm{D})=219.1 \pm 0.4$ mas $\mathrm{yr}^{-1}$ versus $\mathrm{V}_{\text {rot }}(3 \mathrm{D})=213.1 \pm 0.5$ mas $\mathrm{yr}^{-1}$. Proximity of the $\omega_{3}$ values in $3 \mathrm{D}$ and $2 \mathrm{D}$ cases can be explained by the fact that rotational components of the OMM $\omega_{1}, \omega_{2}, \omega_{3}$ do not have projections onto radial direction. However, there are small differences of order of 0.020.06 mas $\mathrm{yr}^{-1}$ caused by redistribution of the OMM parameter values when using the LSM.

It is well known that the stellar velocity field in the Solar neighborhood can be disturbed by influence of the Gould Belt stars the characteristic radius of which is estimated to be $\sim 500 \mathrm{pc}$. We removed stars with distances up to 500 pc from the YRCG subsample resulting in 15,600 stars within a distance range 500 $1200 \mathrm{pc}$. The OMM parameters were recalculated for the second YRCG subsample using the 3D and 2D Gaia DR2 data. The results are shown in columns 5,6 of Table 1. It can be seen that values of the OMM parameters derived from the $3 \mathrm{D}$ and $2 \mathrm{D}$ Gaia DR2 data have become much more consistent. So, one can make a conclusion that a probable cause of the discrepancy between $3 \mathrm{D}$ and $2 \mathrm{D}$ calculations can be peculiarities of motions of the Gould Belt stars.

As for the $K_{x y}$-term, it has a negative values when using radial velocities: $K=-0.84 \pm 0.05{\mathrm{mas} \mathrm{yr}^{-1} \text { and }}^{-1}$

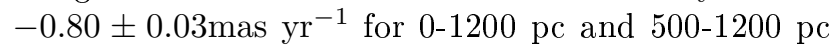
stellar subsamples respectively. It means that the stellar subsample contracts. The $K_{x y}$-term becomes insignificant within $3 \sigma$ when using proper motions only.

In columns 4 and 7 of Table 1 values of the OMM parameters derived from the PMA proper motions are presented. Note a quite large difference between values of the $M_{12}^{+}$parameter derived from the Gaia DR2 and PMA data leading to a lower estimation of $\mathrm{V}_{\text {rot }}$ $205.2 \pm 0.5 \mathrm{~km} \mathrm{~s}^{-1}$ from the PMA proper motions versus $217.8 \pm 0.3 \mathrm{~km} \mathrm{~s}^{-1}$ from the Gaia DR2 proper motions. Values of the $K_{x y}$ term derived from the PMA data is insignificant within $3 \sigma$.

The mean age of the YRCG subsample can be estimated from values of the Solar motion component along the y Galactic axis $Y_{\odot}$. According to Gontcharov (2012b), the older stars the higher $Y_{\odot}$ It can be seen from our calculations that values of the $Y_{\odot}$ parameter vary from $10.6 \pm 0.21 \mathrm{~km} \mathrm{~s}^{-1}$ to $13.40 \pm 0.22 \mathrm{~km} \mathrm{~s}^{-1}$ depending on data used. This fact means that ages of stars belonging to the selected YRCG subsample do not exceed 2 bln years, as we expected.

Values of the Solar apex coordinate $\mathrm{L}_{\odot}$ vary from $44^{\circ} .9 \pm 0^{\circ} .3$ to $51^{\circ} .5 \pm 0^{\circ} .1$ depending on data used. Values of the $\mathrm{B}_{\odot}$ are sistematically shifted when using different stellar subsamples. $\mathrm{B}_{\odot}$ in average is equal to $27^{\circ} .2$ for the $0-1200$ pc stellar subsample while $23^{\circ} .7$ for the 500-1200 pc one.

\section{Conclusions}

Kinematic analisys of the stellar velocity field of the YRCG with distances up to 1200 pc using the OMM was caried out. The kinematic parameters from the 3D, 2D Gaia DR2 and PMA data were derived. It was concluded that the stellar velocity field within 500 pc around the Sun is probably disturbed by influence of the Gould Belt stars. When removing stars with distances $0-500 \mathrm{pc}$ from the YRCG subsample the results derived from the 3D and 2D Gaia DR2 data become consistent.

Value of the rotation velocity of the Galaxy at the Solar distance $V_{\text {rot }}$ derived from the PMA data for the $500-1200$ pc subsample is lower by $13.4 \mathrm{~km} \mathrm{~s}^{-1}$ and $12.6 \mathrm{~km} \mathrm{~s}^{-1}$ than values derived from the $3 \mathrm{D}$ and $2 \mathrm{D}$ Gaia DR data respectively. $\quad \mathrm{V}_{\text {rot }}(\mathrm{PMA})=205.2 \pm$ $0.5 \mathrm{~km} \mathrm{~s}^{-1}, \mathrm{~V}_{\text {rot }}(2 \mathrm{D}$ Gaia DR2 $)=217.8 \pm 0.3 \mathrm{~km} \mathrm{~s}^{-1}$, $\mathrm{V}_{\text {rot }}(2 \mathrm{D}$ Gaia DR2 $)=218.6 \pm 0.3 \mathrm{~km} \mathrm{~s}^{-1}$.

The $K_{x y}$-term is negative and equal to $-0.80 \pm$ 0.03 mas $\mathrm{yr}^{-1}$ when using $3 \mathrm{D}$ Gaia DR2 data while it diminishes in case of usage of Gaia DR2 and PMA proper motions.

Acknowledgements. This work has made use of data from the European Space Agency (ESA) mission Gaia (https://www.cosmos.esa.int/gaia), processed by the Gaia Data Processing and Analysis Consortium (DPAC, https://www.cosmos.esa.int/web/gaia/dpac/ consortium). Funding for the DPAC has been provided by national institutions, in particular the institutions participating in the Gaia Multilateral Agreement.

\section{References}

Akhmetov V.S., Fedorov P.N., Velichko A.B., Shulga V.M.: 2017, MNRAS, 469, 1.

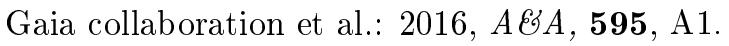

Gaia collaboration et al.: 2018b, $A \& A$, 616, A1.

Girardi L.: 1999, MNRAS, 308, 818-832.

Girardi L. Groenewegen M.A.T., Weiss A., Salaris M.: 1998, MNRAS, 301, 149.

Gontcharov G.A.: 2012, Spatial distribution of stars, their kinematics and interstellar absorption in the nearest kiloparsec ( $\mathrm{PhD}$ thesis)

Gontcharov G.A.: 2012b, Astron. Lett.,38, 12 .

Gontcharov G.A.: 2017, Astron. Lett., 43, 7, 472-488.

Vallée G. A.: 2017, Ap\&SS, 362, 79V.

Ogorodnikov K. F.: 1965, Dynamics of stellar systems, Fizmatgiz, Moscow [in russian] 